Research Article

\title{
Improving the Moisture Sensitivity of Asphalt Mixtures by Simultaneous Modification of Asphalt Binder and Aggregates with Carbon Nanofiber and Carbon Nanotube
}

\author{
Mohammad Nikookar, ${ }^{1}$ Mojtaba Bagheri Movahhed, ${ }^{2}$ Jalal Ayoubinejad, ${ }^{3}$ \\ Vahid Najafi Moghaddam Gilani (i), ${ }^{4}$ and Seyed Mohsen Hosseinian (1) ${ }^{4}$ \\ ${ }^{1}$ Department of Civil Engineering, University of Guilan, Rasht, Iran \\ ${ }^{2}$ Department of Civil Engineering, Payame Noor University, Kish, Iran \\ ${ }^{3}$ Department of Civil Engineering, Payame Noor University, Tehran, Iran \\ ${ }^{4}$ Department of Civil Engineering, Iran University of Science and Technology, Tehran, Iran
}

Correspondence should be addressed to Vahid Najafi Moghaddam Gilani; vahid.moghaddam90@gmail.com

Received 25 December 2020; Revised 3 March 2021; Accepted 12 March 2021; Published 25 March 2021

Academic Editor: Valeria Vignali

Copyright $\odot 2021$ Mohammad Nikookar et al. This is an open access article distributed under the Creative Commons Attribution License, which permits unrestricted use, distribution, and reproduction in any medium, provided the original work is properly cited.

\begin{abstract}
Moisture sensitivity of asphalt mixtures may cause damage due to cohesion in asphalt binder membrane and adhesion between aggregate and asphalt binder that result in considerable damage to the pavements. Therefore, by determining the adhesion quality in a modified aggregate-asphalt binder system, one can choose the suitable material compositions to decrease the moisture sensitivity of mixtures. In this study, the effects of modified asphalt binder with carbon nanofiber and modified aggregates with carbon nanotube on the moisture sensitivity of asphalt mixtures were simultaneously explored. For investigating the moisture sensitivity, the indirect tensile strength test and surface free energy concept were implemented. The results of the indirect tensile strength test revealed that modification of asphalt binder and aggregates with carbon nanofiber and carbon nanotube, respectively, increased the indirect tensile strength and tensile strength ratio values of mixtures. The results of surface free energy indicated that using carbon nanofiber and carbon nanotube enhanced the adhesion free energy of the aggregate-asphalt binder system. Moreover, utilizing carbon nanofiber to modify asphalt binder enhanced the cohesion free energy values in the asphalt binder membrane. Also, carbon nanofiber and carbon nanotube brought detachment energy of the system toward zero, indicating less desire for the mixtures to be stripped. Generally, investigations performed by the two methods showed that covering aggregates by carbon nanotube as well as utilizing carbon nanofiber as an asphalt binder modifier had a positive impact on decreasing moisture sensitivity of asphalt mixtures.
\end{abstract}

\section{Introduction}

Moisture sensitivity improvement of asphalt mixtures has always been one of the most significant concerns of researchers in the field of pavement engineering science. With the increasing advancement of science and impressive expansion of the use of nanomaterials and other additives in various fields of civil engineering [1-4], pavement engineers were also present in this scientific competition and made extensive attempts to improve the performance of asphalt mixtures [5-8]. In fact, researchers have always sought to apply any kind of additive for improving the primary engineering properties and find an optimal and economical solution $[9,10]$.

One of the significant typical damage types in asphalt pavements is the damage caused by moisture. Moisture results in weakening adhesion between aggregates and asphalt binder and separating them together. This damage is generally called stripping, which can result in holes on the road surfaces and traffic accidents [11-16]. Moisture sensitivity can generally be classified into two categories, including adhesion and cohesion losses. Adhesion loss 
happens when water is placed between the aggregates and asphalt binder and separates the layer of asphalt binder from the surface of aggregates. However, cohesion loss is the result of changing the properties of asphalt binder due to its relationship with water. The moisture sensitivity might be due to each of these two reasons or a combination of both $[17,18]$. Cohesion free energy (CFE) and adhesion free energy (AFE) represent the surface free energy (SFE) concept [19].

One of the most commonly used methods for reducing the moisture sensitivity in asphalt mixtures is the utilization of antistripping materials to modify the properties of aggregate [20-22] or asphalt binder [23-26]. In fact, for obtaining good adhesion in an aggregate-asphalt binder system, the surfaces of both should be changed using a suitable additive in order to enhance the oil friendship and hydrophobicity characteristics of aggregates and asphalt binder cohesion $[27,28]$. So, for obtaining higher performance of asphalt mixtures to moisture, it is better to modify the characteristics of asphalt binder and aggregates simultaneously. To this aim, the two additives of carbon nanofiber (CNF) and carbon nanotube (CNT) have been used to modify the characteristics of aggregates and asphalt binder, respectively. Furthermore, the SFE method and indirect tensile strength (ITS) test have been implemented. The main reason for asphalt binder modification is the reduction of the acidic properties and the increase in the nonpolar properties of asphalt binder, which will result in improved adhesion in the asphalt system. Moreover, the reason for modifying aggregates with nanomaterials is to be able to reduce the hydrophilicity of aggregates [29, 30].

CNTs are hydrophobic nanomaterials that have twodimensional hexagonal networks of carbons with a onedirection connection for creating a hollow cylinder, which results in hydrophobicity and oil friendship characteristics. On the other hand, CFNs are nanomaterials with grapheme layers tidied like cylinders. They can improve the characteristics of asphalt binder due to hydrophobic properties $[31,32]$, which are extensively used in various systems such as composites. This is mainly due to their unique properties as well as low cost. Research studies on using CNF can present a beneficial guide for studying CNT mixing in aggregates because of the resemblance of CNT and CNF. However, CNT presents a higher surface-area-to-volume ratio and aspect ratio $[33,34]$. Briefly, the goals of this research are conducting a classical asphalt binder test to explore the physical properties of modified asphalt binder, investigating the moisture performance of asphalt mixtures by the ITS test, and evaluating the influence of CNF as an asphalt binder modifier and CNT as an aggregate modifier on the behavior of mixtures to moisture using SFE concept.

Many research studies have examined the effects of CNF, CNT, and carbon fibers on the specifications of asphalt mixtures. However, few studies have investigated the impacts of these materials, especially $\mathrm{CNF}$, on the moisture sensitivity of asphalt mixtures.

Abtahi et al. [35] in their study stated that carbon fiber might improve the tensile resistance of asphalt mixtures due to its great tensile resistance. Khattak et al. [31] showed that CNF enhanced adhesion properties in the asphalt system. It also increased the ITS value of mixtures. Ziari et al. [36] explored the impact of CNT on the asphalt binder performance and showed that CNT enhanced the softening point and penetration index and decreased the penetration of asphalt binder compared to the unmodified one. Park et al. [37] indicated that the ITS amount of $0.5 \%$ and $1 \%$ carbon fiber was less than the base sample, but $1.5 \%$ carbon fiber had a higher ITS compared to the base sample. Gong et al. [34] showed that CNT increased the softening point and reduced the penetration of asphalt binder. Saltan et al. [38] in their research showed that using CNT enhanced the asphalt performance in moisture sensitivity. Yoo et al. [39] investigated the effect of $0.5 \%$ and $1 \%$ carbon fiber and $0.5 \% \mathrm{CNT}$ on the characteristics of asphalt mixtures. They showed that using CNT had a greater impact on enhancing ITS compared to using carbon fiber. The ITS amount of carbon fiber was even less than or equal to the base sample. Ameli et al. [40] showed that CNT increased penetration index, ITS, and moisture resistance of asphalt mixtures. Amini and Hayati [41] indicated that using 1.5\% CNT improved the ITS and tensile strength ratio (TSR) values of asphalt samples.

Surface free energy (SFE) has been extensively explored by researchers in asphalt pavements. In a study performed by Kakar et al. [42], moisture sensitivity and SFE were explored in asphalt binders which were modified using surfactant-based materials. Results showed that SFE was decreased by the mentioned additive. Sakanlou et al. [21] reported that adhesion free energy of aggregate-asphalt binder was reduced using hydrated lime. Hamedi [22] examined the impact of nanocoating on the aggregate surface in exploring moisture damage, and results presented using the SFE concept showed that the differences between AFE in the presence of water and dry condition were decreased by the use of nanoparticles and, therefore, the stripping phenomenon was reduced. In another research conducted by Hamedi et al. [43] by the use of SFE and thermodynamic theories, the aggregate-asphalt binder adhesion and asphalt binder membrane cohesion were evaluated by the utilization of some antistripping materials under dry and wet conditions. They reported that the AFE between asphalt binder and acidic aggregates increased by the use of polar copolymer material.

\section{Experimental Design}

In this study, a type of limestone aggregate and base asphalt binder penetration grade $60 / 70$ as well as antistripping agents of CNT and CNF were used, where the process of the research is indicated in Figure 1.

2.1. Aggregate. In the present study, limestone was applied, the gradation of which was based on ASTM standard that the maximum and nominal aggregate sizes are $1.9 \mathrm{~cm}$ and $1.25 \mathrm{~cm}$, respectively. The gradation structure is displayed in Figure 2. Table 1 also illustrates the physical specifications of aggregate. 


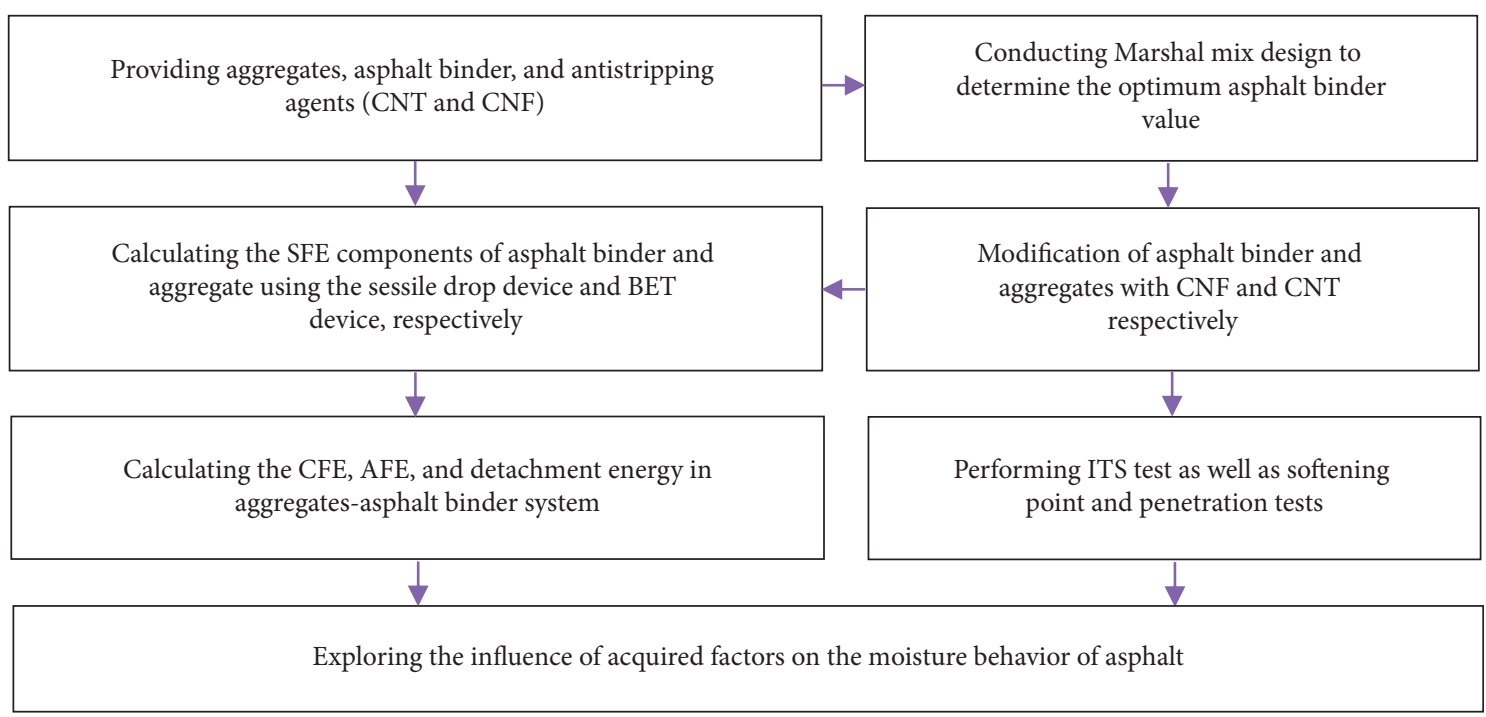

FIgURE 1: The process of the research method.

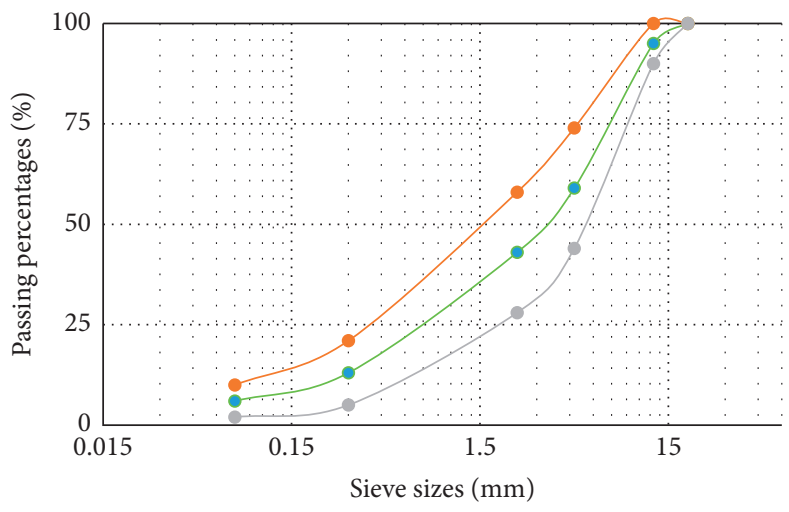

Figure 2: The gradation of aggregate used.

TABLE 1: The physical specifications of aggregate.

\begin{tabular}{lccc}
\hline Specifications & Limestone & Regulation limit & Standard \\
\hline Specific gravity (filler) & 2.56 & - & ASTM D854 \\
\hline Specific gravity (fine aggregate) & \multicolumn{2}{c}{} & - \\
$\quad$ Apparent & 2.60 & - & ASTM C128 \\
Bulk & 2.57 & - & - \\
$\quad$ Effective & 2.56 & - & ASTM C127 \\
Specific gravity (coarse aggregate) & 2.63 & Maximum 15 & \\
$\quad$ Apparent & 2.61 & Maximum 10 & ASTM C88 \\
Bulk & 2.60 & Maximum 2 & ASTM D5821 \\
Effective & 2 & Maximum 15 & ASTM C127 \\
Sodium sulfate soundness & 88 & Maximum 30 & ASTM D4791 \\
Flat and elongated particles & 0.8 & 3 & ASTM C131 \\
Maximum water absorption & 28 & & \\
Needle and flake particles & & & \\
Maximum Los Angeles abrasion &
\end{tabular}

2.2. Asphalt Binder. Base asphalt binder penetration grade $60 / 70$ was used in this research, and its classical tests were conducted according to the ASTM standards to determine the rheology characteristics of base asphalt binder.
2.3. Antistripping Additives. For exploring the influence of antistripping materials on the moisture sensitivity of asphalt mixtures, CNT additive was used as the cover for the base aggregates and CNF additive was utilized as the modifier of base asphalt binder. 
2.4. Preparation of the Modified Aggregates and Asphalt Binder. For covering the aggregates with CNT, the slurry was first made by the addition of 1 unit of CNT to 10 and 20 units of water using a $200 \mathrm{rpm}$ mixer for 4 minutes with a homogeneous distribution of nanoparticles. The aggregates were then purred to the slurry of nanomaterials and stirring was proceeded at $120 \mathrm{rpm}$ for 2 minutes until the whole surface of aggregates was covered by slurry. Finally, the wet aggregates were exposed for 24 hours to 110 degrees so that their moisture content was evaporated and the aggregates were coated by CNT. CNT was absorbed by the surface of aggregates to the amount of 1.3 and 2.4 weight percent. Also, in order to modify the asphalt binder characteristics, CNF was used so that one could investigate the impact of the simultaneous modification of asphalt binder and aggregates on their adhesion and cohesion characteristics. Firstly, in order to mix $1 \%$ and $2 \% \mathrm{CNF}$ as an asphalt binder modifier, the asphalt binder was heated to 150 degrees and slowly poured into the mixing bowl at $12000 \mathrm{rpm}$, and the mix operation proceeded for 20 minutes. Moreover, in this study, based on AASHTO T245, the Marshall mix design was applied for the specification of the optimum asphalt binder [44], according to the mean amounts of three various asphalt binders based on $4 \%$ air voids and the greatest specific gravity and Marshall strength. The optimal asphalt binder percentage was measured by $4.9 \%$.

\section{Tests}

3.1. Exploration of Physical Properties. In order to investigate the physical properties of modified and unmodified asphalt binders, the softening point and penetration tests were performed according to ASTM D36 and ASTM D5, respectively $[45,46]$. The classical test results were used to determine the penetration index (PI), which is considered as an asphalt sensitivity measure to variation of temperature [47] and is described as equation (1) as a function of penetration degree and softening point of asphalt mixtures.

$$
\mathrm{PI}=\frac{20-500 X}{1+50 X} \longrightarrow X=\frac{\log 800-\log P}{T_{\mathrm{RB}}-t},
$$

in which $T_{\mathrm{RB}}$ represents softening point and $P$ illustrates penetration at $t$ degree.

3.2. ITS Test. ITS test was performed in this research to examine the moisture behavior of asphalt due to using antistripping additives, in accordance with AASHTO T283. So, mixtures were first saturated with water for 5 minutes in order to simulate wet conditions. They were then kept for 5-10 minutes without vacuum and in submerged conditions. After they got saturated, they were stored for 16 hours in a freezer at -18 degrees. They were then held in a water bath for 24 hours at 60 degrees and then were returned to a place with 25 degrees and were held for 24 hours at the same degree. The load was recorded for performing ITS test until rupture and the amount of ITS ( $\mathrm{kPa})$ was measured $[48,49]$ :

$$
\text { ITS }=\frac{2 P}{t \pi d}
$$

where $d$ represents the mixture diameter (m), $P$ presents the rupture force $(\mathrm{kN})$, and $t$ presents the mixture thickness $(m)$. The wet-to-dry tensile strength ratio for investigation of the moisture sensitivity of mixtures was measured [50,51]:

$$
\mathrm{TSR}=\frac{\mathrm{ITS}_{\mathrm{wet}}}{\mathrm{ITS}_{\text {dry }}} \times 100,
$$

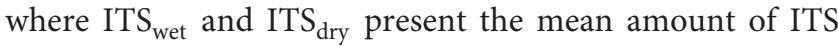
under wet and dry conditions, respectively $(\mathrm{kPa})$.

3.3. Measurement of the SFE Components. In order to calculate the SFE components of aggregates and asphalt binders, various approaches can be used. The SFE of aggregates in this study was measured by the BET device [52], and the asphalt binder SFE was calculated using the sessile drop device [53].

For representing the SFE components of materials, the theory of acid-base is one of the significant theories widely utilized [54]. In the aforementioned theory, based on the molecules' forces in the surface, the total SFE for each material has three classifications of acidic, basic, and nonpolar components and is defined as

$$
\Gamma^{\text {total }}=\Gamma^{\mathrm{AB}}+\Gamma^{\mathrm{LW}}
$$

where $\Gamma^{\text {total }}$ presents the substance total SFE, and $\Gamma^{\mathrm{LW}}$ and $\Gamma^{\mathrm{AB}}$ represent the nonpolar and polar components of SFE, respectively. The polar component is described by the Lewis acid $\left(\Gamma^{+}\right)$and Lewis base $\left(\Gamma^{-}\right)$as

$$
\Gamma^{\mathrm{AB}}=2 \sqrt{\Gamma^{-} \Gamma^{+}} .
$$

CFE, more precisely $\Delta \mathrm{G}^{c}$, is defined thermodynamically as the energy required to create a crack inside the material and is illustrated as

$$
\Delta G^{c}=2 \Gamma^{\text {total }} .
$$

The aggregate-asphalt binder AFE $\left(\Delta \mathrm{G}_{i}^{a}\right)$ consists of the following two components:

$$
\Delta G_{i}^{a}=\Delta G_{i}^{a \mathrm{AB}}+\Delta G_{i}^{a \mathrm{LW}}=2\left[\sqrt{\Gamma_{s}^{+} \Gamma_{l}^{-}}+\sqrt{\Gamma_{s}^{-} \Gamma_{l}^{+}}+\sqrt{\Gamma_{s}^{\mathrm{LW}} \Gamma_{l}^{\mathrm{LW}}}\right],
$$

where $\Delta \mathrm{G}_{i}^{a \mathrm{LW}}$ and $\Delta \mathrm{G}_{i}^{a \mathrm{AB}}$ present the nonpolar and polar components of AFE, respectively, $\Gamma_{s}^{\mathrm{LW}}, \Gamma_{s}^{+}$, and $\Gamma_{s}^{-}$represent the aggregate $\mathrm{SFE}$ components, and $\Gamma_{l}^{\mathrm{LW}}, \Gamma_{l}^{-}$, and $\Gamma_{l}^{+}$illustrate the asphalt binder SFE components.

For the calculation of aggregate-asphalt binder AFE in the presence of water, equation (8) can be utilized, and the indices of 1-3 present asphalt binder, aggregate, and water, respectively. The negative values of AFE indicate the inclination of materials for debonding from each other, and the greater this inclination, the more negative amount [55]. 


$$
\begin{aligned}
\Delta G_{132}^{a} & =\Gamma_{12}-\Gamma_{13}-\Gamma_{23} \\
& =-2\left[\Gamma_{3}^{\mathrm{LW}}+2 \sqrt{\Gamma_{3}^{+} \Gamma_{3}^{-}}-\sqrt{\Gamma_{1}^{\mathrm{LW}} \Gamma_{3}^{\mathrm{LW}}}-\sqrt{\Gamma_{3}^{+} \Gamma_{1}^{-}}-\sqrt{\Gamma_{1}^{+} \Gamma_{3}^{-}}-\sqrt{\Gamma_{2}^{\mathrm{LW}} \Gamma_{3}^{\mathrm{LW}}}-\sqrt{\Gamma_{3}^{+} \Gamma_{2}^{-}}-\sqrt{\Gamma_{2}^{+} \Gamma_{3}^{-}}+\sqrt{\Gamma_{1}^{\mathrm{LW}} \Gamma_{2}^{\mathrm{LW}}}+\sqrt{\Gamma_{1}^{+} \Gamma_{2}^{-}}+\sqrt{\Gamma_{2}^{+} \Gamma_{2}^{-}}\right] .
\end{aligned}
$$

\section{Results and Discussion}

4.1. Rheology Characteristics of Asphalt Binder. In this study, base asphalt binder penetration grade $60 / 70$ was used, where its characteristics by conducting the classical tests according to the ASTM standards are illustrated in Table 2. Also, the penetration and softening point test results are represented in Table 3. As is obvious, CNF decreased the penetration degree and increased the softening point of the asphalt binder. $11.67 \%$ and $17.72 \%$ of the penetration reduced by the addition of $1 \%$ and $2 \% \mathrm{CNF}$ to the base asphalt binder, respectively. In fact, the asphalt binder stiffness was increased using CNF. Moreover, the addition of CNF under the same stresses makes the mixtures bear less strain. In mixtures made with $1 \%$ and $2 \% \mathrm{CNF}$, the softening point was enhanced by $16.84 \%$ and $29.94 \%$, respectively. Also, for the exploration of the temperature sensitivity of the CNF modified asphalt binder, PI was measured from the penetration and softening point test results, as seen in Table 3. Greater PI values represent lower asphalt binder sensitivity to a temperature that causes greater resistance of an asphalt mixture to permanent deformations. PI amounts were enhanced because of the CNF value growth that illustrates less change in the sensitivity of asphalt binders against temperature fluctuations.

Various studies [34, 36, 40] have indicated that using $\mathrm{CNT}$ as an asphalt binder modifier enhanced the softening point and penetration index and decreased penetration of asphalt binder compared to the unmodified one; however, there have been limited studies on the effect of CNF on the penetration index of modified asphalt binder.

4.2. ITS. The ITS results of mixtures under dry and wet conditions are presented in Figure 3. As is clear, with the cohesion loss of asphalt mixtures due to the exposure of the mixtures to the moisture, the ITS values of the mixtures in wet conditions were decreased in comparison with those of mixtures in dry conditions. The ITS amounts in both wet and dry conditions were enhanced by modifying the characteristics of the aggregates with CNT. With the addition of CNF as an antistripping additive to the asphalt binder, the adhesion and cohesion of the mixtures were enhanced and resulted in greater moisture resistance compared to the unmodified mixture. The ITS amount of mixtures modified with $1.3 \%$ and $2.4 \%$ CNT and $1 \%$ and $2 \%$ CNF was increased by $7.93 \%, 14.39 \%, 4.18 \%$, and $9.94 \%$ in dry condition and $19.31 \%, 34.03 \%, 13.06 \%$, and $27.92 \%$ in wet condition, respectively, compared to the unmodified mixture. Further, the simultaneous modification of the aggregates and asphalt binder with $1.3 \% \mathrm{CNT}+1 \% \mathrm{CNF}$ and $2.4 \% \mathrm{CNT}+2 \%$ CNF caused the resistance of modified asphalt mixtures to improve by $26.24 \%$ and $52.92 \%$ in dry condition and $57.64 \%$ and $102.92 \%$ in wet condition, in comparison with the unmodified mixture, respectively. The greatest increment in the ITS value was evident in the modified mixtures with $2.4 \% \mathrm{CNT}+2 \% \mathrm{CNF}$. Therefore, modification of aggregates and asphalt binder simultaneously is better for improving the resistance of asphalt mixtures against moisture sensitivity.

Figure 4 illustrates the TSR amounts of mixtures. As is evident, the TSR values of the modified mixtures with $1.3 \%$ and $2.4 \% \mathrm{CNT}$ and $1 \%$ and $2 \% \mathrm{CNF}$ compared to the base mixture increased by $10.54 \%, 17.17 \%, 8.51 \%$, and $16.35 \%$, respectively. Moreover, the simultaneous utilization of $1.3 \%$ $\mathrm{CNT}+1 \% \mathrm{CNF}$ and $2.4 \% \mathrm{CNT}+2 \% \mathrm{CNF}$ caused the resistance of modified asphalt mixtures to improve by $24.87 \%$ and $32.69 \%$ compared to the base mixture, respectively. The simultaneous application of CNT as an aggregate modifier and $\mathrm{CNF}$ as an asphalt binder modifier illustrated the greatest influence on increasing the resistance of asphalt mixtures to moisture sensitivity. Also, the results indicated that the single utilization of additives could not conclude the significant effects, and it is better to use the additive materials in all asphalt mixture compositions such as asphalt binder and aggregates. Using additive materials in modifying the asphalt binder can help to decrease the polar properties and, therefore, increase the adhesion of asphalt mixtures in the presence of water or dry condition. On the other hand, modifying the aggregates with the additive materials can increase the hydrophobic properties and adhesion with asphalt binder.

Moreover, considering the acceptable TSR threshold of $70 \%$, it can be seen that the mixtures modified with $2.4 \%$ CNT (as the aggregate modifier), 2\% CNF (as the asphalt binder modifier), $1.3 \% \mathrm{CNT}+1 \% \mathrm{CNF}$, and $2.4 \% \mathrm{CNT}$ and $2 \% \mathrm{CNF}$ (as the simultaneous application) can enhance the moisture resistance of asphalt mixtures.

The results presented in this section are consistent with the study of Khattak et al. [31], which indicated that CNF improved the tensile resistance of asphalt mixtures. A similar finding was presented by Najafi Moghaddam Gilani et al. [18], which illustrated that using CNT reduced the stripping potential of mixtures. Moreover, Saltan et al. [38] showed that using CNT enhanced the asphalt performance in moisture sensitivity, which is also in accordance with the results of this research. However, the simultaneous utilization of CNT and CNF, as illustrated in this study, can further improve the tensile resistance of asphalt mixtures. 
TABLE 2: The characteristics of base asphalt binder.

\begin{tabular}{lcc}
\hline Characteristics & Standard & Base asphalt binder \\
\hline Penetration grade $(0.1 \mathrm{~mm})$ & ASTM D5 & 69 \\
Penetration ratio & ASTM D1754 & 0.25 \\
\hline Heat weight loss (\%) & ASTM D92 & 0.75 \\
Flash point (0C) & ASTM D113 & 264 \\
Ductility (cm) & ASTM D36 & 114 \\
Softening point (0C) & & 48 \\
\hline
\end{tabular}

TABLE 3: Penetration and softening point amounts.

\begin{tabular}{lccc}
\hline Asphalt binder type & Softening point $(0 \mathrm{C})$ & Penetration $(\mathrm{mm})$ & PI \\
\hline Base & 48.1 & 69.4 & -0.9039 \\
Modified with 1\% CNF & 56.2 & 61.3 & 0.7609 \\
Modified with 2\% CNF & 62.5 & 57.1 & 1.8642 \\
\hline
\end{tabular}

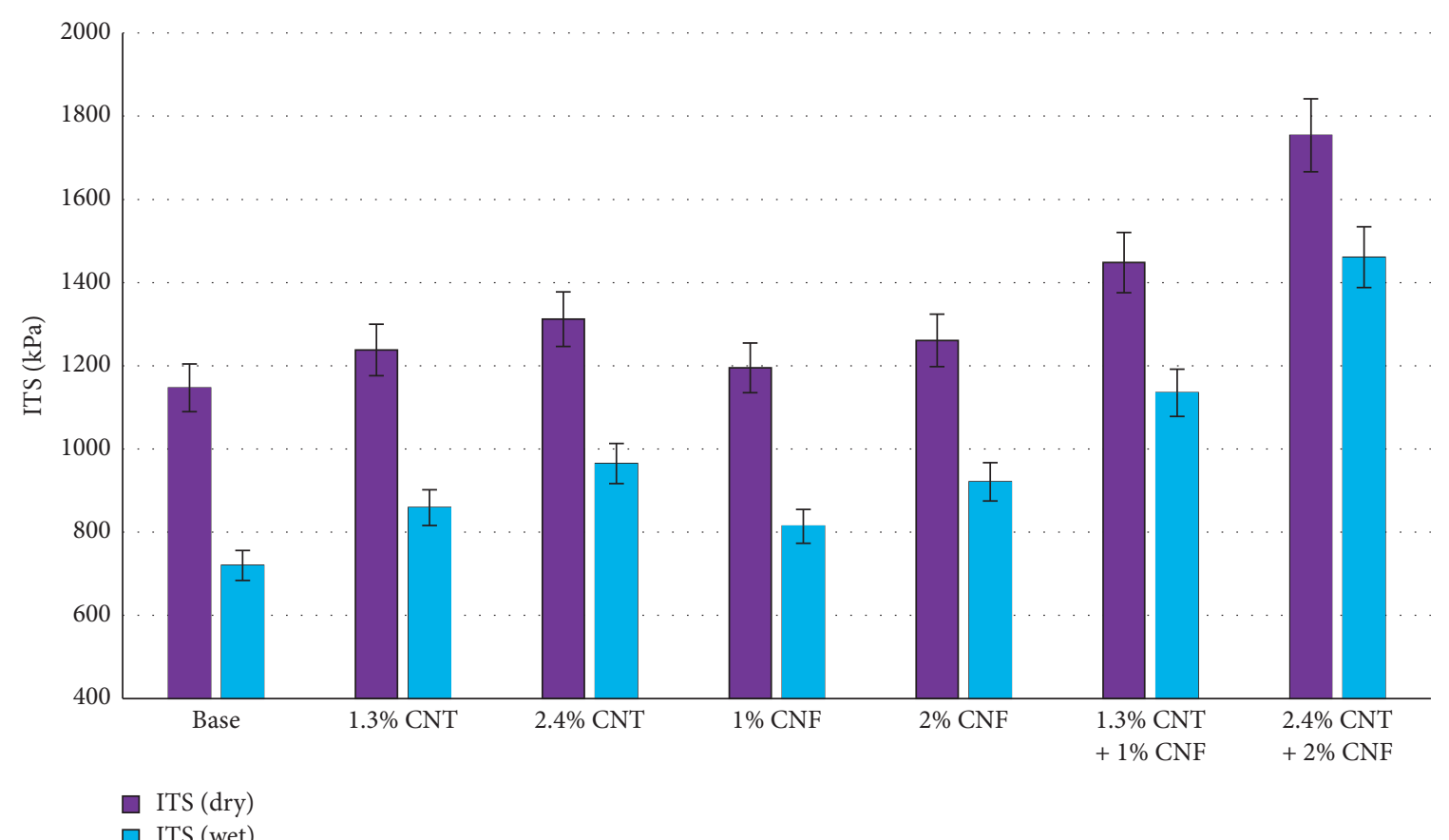

FIgURE 3: The results of the ITS test in wet and dry conditions.

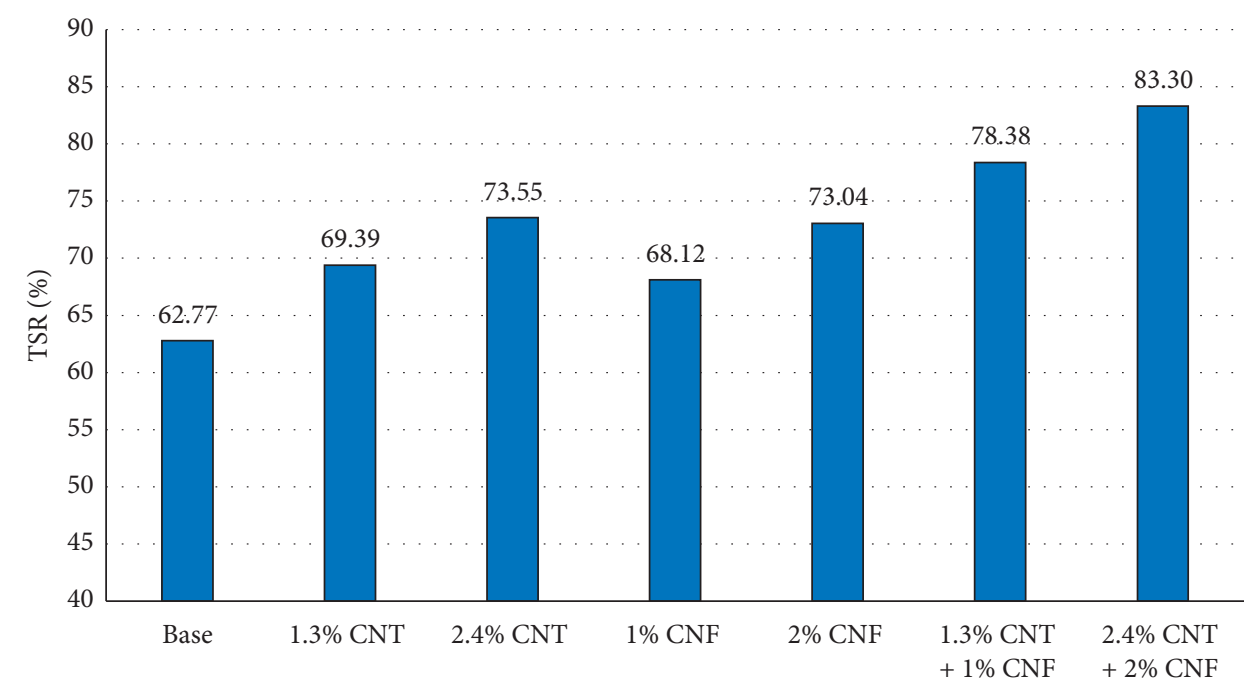

FIgURE 4: The results of TSR of base and modified asphalt mixtures. 


\subsection{Surface Free Energy (SFE)}

4.3.1. Measurement of the Aggregate SFE Components. The results of the measurements of the aggregate SFE components associated with the unmodified and modified aggregates are represented in Table 4. As is evident, the acidic and polar components of aggregates were reduced by modifying their properties with CNT. This indicates the reduction in the tendency of aggregates for detachment from the asphalt binder's surface in the presence of water as a polar substance. Also, it was evident that the nonpolar and basic SFE components of modified aggregates were higher than the unmodified ones. In other words, by creating a coating on the surface of aggregates, their hydrophilic properties decreased and led to the formation of nonpolar bonds and more resistance to moisture damage, as a consequence. Therefore, limestone $+2.4 \% \mathrm{CNT}$ had the highest moisture resistance, and its tendency for detachment from the surface of asphalt binder was the lowest among the other aggregates investigated.

\subsubsection{Measuring the Asphalt Binder SFE Components.} The SFE components of the unmodified and modified asphalt binders are represented in Table 5. As is obvious, the addition of CNF enhanced the total SFE value of asphalt binder, showing that further energy is required for the cohesion type failure that can enhance the moisture resistance. Moreover, the asphalt binder polar components were smaller than the asphalt binder nonpolar ones. So, considering that the nonpolar component is the bulk of the total asphalt binder SFE, it can be said that the bonding of asphalt binder with other substances is basically through the nonpolar component. The addition of CNF remarkably enhanced the modified asphalt binder nonpolar components associated with the total SFE increment of modified asphalt binder and their failure resistance. On the other hand, using $\mathrm{CNF}$ in addition to improving the nonpolar components also raised the polar components of the modified asphalt binders associated with a decrease in the acidic components and an increment in the basic components of the modified asphalt binders that can enhance the adhesion of these types of asphalt binders with aggregates. Therefore, the modified asphalt binder with $2 \% \mathrm{CNF}$ had the greatest adhesion with the aggregates among the other asphalt binders explored.

4.3.3. AFE. The AFE amounts were calculated at the contact surface of the modified and unmodified aggregates and asphalt binders using the SFE components of asphalt binder (Table 5) and aggregate (Table 4), and Figure 5 presents the results. As is clear, the separation of modified asphalt binder from the surface of aggregates was difficult in dry conditions (without the presence of water) and needed further energy. Indeed, applying $\mathrm{CNF}$ as an asphalt binder modifier and CNT as an aggregate modifier enhanced the AFE between asphalt binder and aggregates. Moreover, by raising $\mathrm{CNT}$ and $\mathrm{CNF}$ contents, the energy needed to fail at the contact surface of asphalt binder and aggregates in dry conditions was enhanced. The simultaneous utilization of $2.4 \%$ CNT $+2 \%$ CNF had the greatest influence on the enhancement of AFE.

Khattak et al. [31], in their study, revealed that using CNF enhanced the adhesion properties in the asphalt system, which is consistent with the results of this study. Also, Najafi Moghaddam Gilani et al. [18] indicated that using CNT slightly increased the AFE of the system. However, according to the results of this study, the simultaneous utilization of CNT and CNF can further improve adhesion in the asphalt system and illustrate that further energy is needed for rupture at the contact surface of aggregates and asphalt binder.

4.3.4. CFE. Figure 6 illustrates the CFE results of the unmodified and modified asphalt binders. Because of the nonpolar components of asphalt binder SFE, much of the increment in asphalt binder resistance to crack was in the asphalt binder membrane and the polar components had little influence on increasing or weakening the resistance of asphalt binder to crack failures and could influence the adhesion of aggregates and asphalt binders more. So, it can be said that applying CNF for the modification of asphalt binder increased the CFE amounts. Therefore, as is illustrated in Figure 6, the modified asphalt binder with $2 \%$ CNF had the highest CFE value in the asphalt binder membrane compared to the other asphalt binders examined.

In a study conducted by Khattak et al. [31], results indicated that using $\mathrm{CNF}$ enhanced the cohesion properties of asphalt binder compared to the unmodified one, indicating that more energy is required for rupture in the asphalt binder membrane, which is in accordance with the results of this research.

4.3.5. Detachment Energy (DE). The DE results between aggregates and asphalt binder in the presence of water are illustrated in Figure 7. As can be seen, the asphalt binderaggregate AFE changed from a positive value in dry conditions to a negative value in the presence of water. So, when aggregate, water, and asphalt binder are in contact, water changes the free energy of the system to reach the lowest state, which is indeed stripping. Applying CNF as an asphalt binder modifier and CNT as an aggregate modifier brought the DE of the system to zero, which illustrates a less tendency of the mixtures to stripping. An increment in CNT and CNF contents decreased this desire. So, mixtures modified with $2.4 \%$ CNT $+2 \%$ CNF because of having the highest DE enhanced the system energy, and stripping will occur later.

Although various studies [21, 22, 42, 43] have investigated the effect of different additives on AFE and CFE in the asphalt system, there have been limited studies on the influence of CNF on DE between aggregates and asphalt binder. Najafi Moghaddam Gilani et al. [18], in their study, revealed that using CNT reduced DE absolute amounts in the asphalt system. However, according to the results of this research, the simultaneous utilization of CNT and CNF can bring the DE of the system toward zero more, showing the less desire of the mixtures to be stripped. 
TABLE 4: : The SFE components of the unmodified and modified aggregates $\left(\mathrm{mJ} / \mathrm{m}^{2}\right)$.

\begin{tabular}{|c|c|c|c|c|c|}
\hline \multirow{2}{*}{ Aggregate } & \multicolumn{5}{|c|}{ SFE components } \\
\hline & $\Gamma^{+}$, acidic & $\Gamma^{-}$, basic & $\Gamma^{A B}$, polar & $\Gamma^{L W}$, nonpolar & $\Gamma^{\text {total }}$ \\
\hline Limestone & 22.20 & 509.93 & 212.80 & 60.71 & 273.51 \\
\hline Limestone $+1.3 \%$ CNT & 19.17 & 514.61 & 198.65 & 72.91 & 271.56 \\
\hline Limestone $+2.4 \% \mathrm{CNT}$ & 16.48 & 519.12 & 184.99 & 74.11 & 259.10 \\
\hline
\end{tabular}

TABLE 5: The SFE components of the unmodified and modified asphalt binders $\left(\mathrm{mJ} / \mathrm{m}^{2}\right)$.

\begin{tabular}{lcccr}
\hline \multirow{2}{*}{ Asphalt binder } & \multicolumn{3}{c}{ SFE components } \\
& $\Gamma^{+}$, acidic & $\Gamma^{-}$, basic & $\Gamma^{\mathrm{AB}}$, polar & $\Gamma^{\mathrm{LW}}$, nonpolar \\
\hline Unmodified & 22.20 & 509.93 & 2.38 & 11.78 \\
Modified with 1\% CNF & 19.17 & 514.61 & 2.50 & 14.34 \\
Modified with 2\% CNF & 16.48 & 519.12 & 2.62 & 17.16 \\
\hline
\end{tabular}

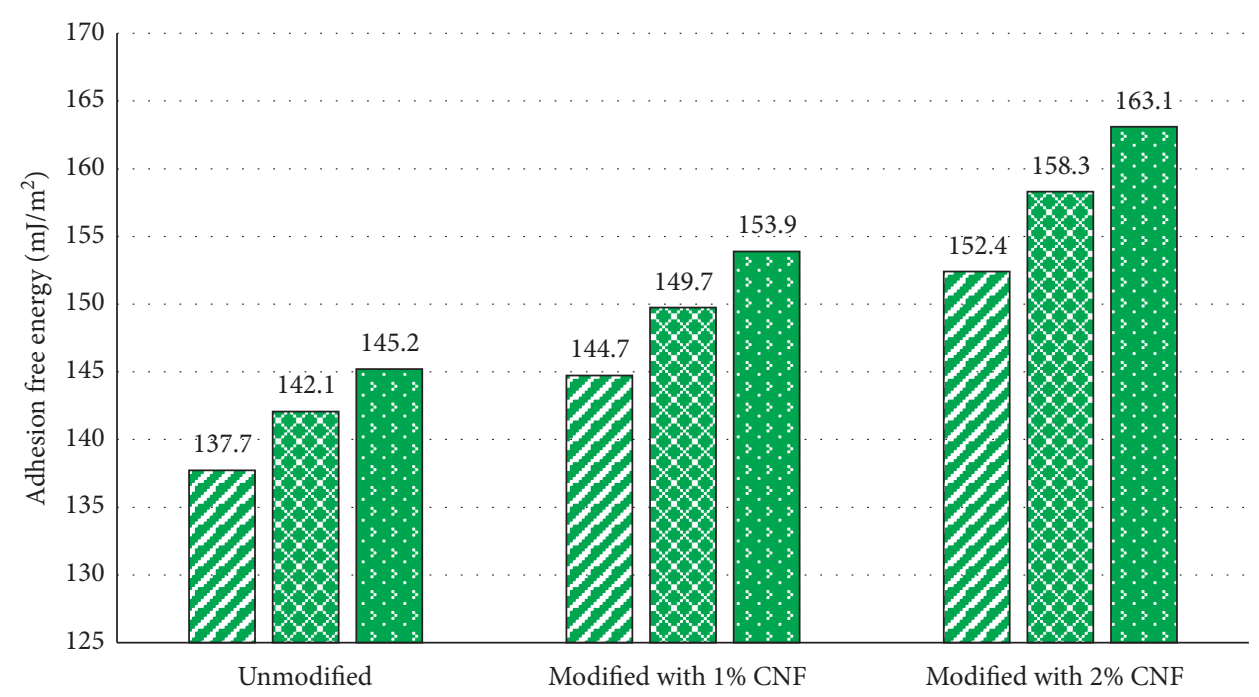

๑ Limestone

Limestone $+1.3 \% \mathrm{CNT}$

๑ Limestone $+2.4 \% \mathrm{CNT}$

FIgURE 5: AFE amounts of aggregates and asphalt binders in dry condition.

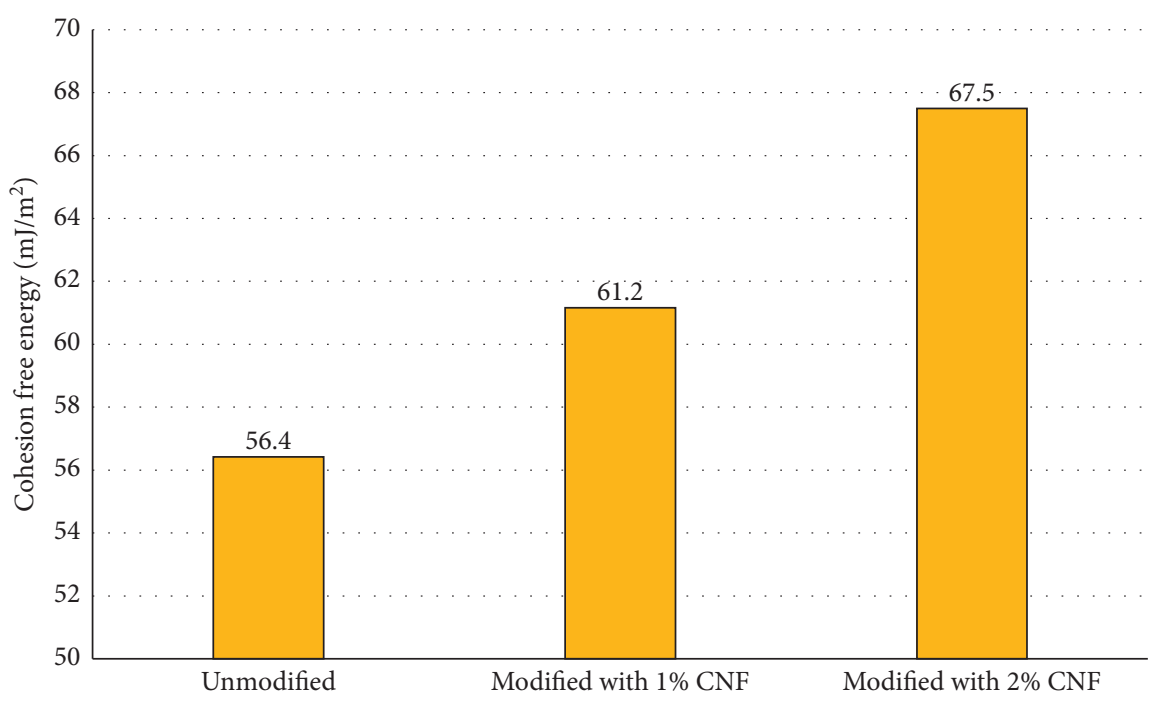

Figure 6: CFE values of base and modified asphalt binders. 


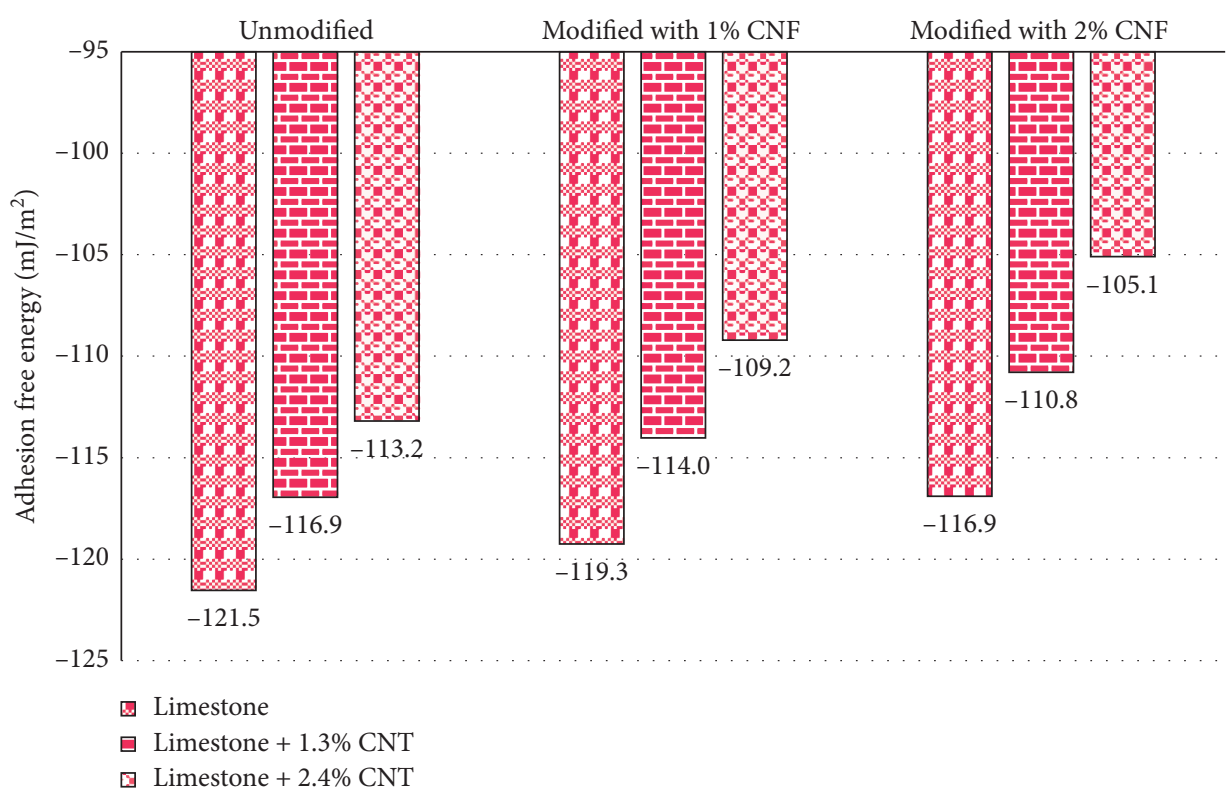

FIGURE 7: DE amounts of the aggregate and asphalt binder in the presence of water.

\section{Conclusion}

In this research, the moisture performance and SFE concept of asphalt mixtures were explored under the influence of CNT and CNF antistripping agents. The simultaneous modification of aggregates and asphalt binder was also carried out to decrease the moisture sensitivity of asphalt mixtures. The significant findings of this study are as follows:

(i) Using CNT as an aggregate modifier reduced the penetration degree and increased the softening point of the modified asphalt binder. Also, these two parameters increased the PI values that improve the sensitivity of modified asphalt binder against temperature variations

(ii) The ITS test results indicated that the modification of asphalt binder and aggregates with CNF and CNT, respectively, enhanced the TSR and ITS values of mixtures

(iii) The simultaneous utilization of $2.4 \%$ CNT $+2 \%$ $\mathrm{CNF}$ resulted in the best effect on increasing the ITS and TSR values

(iv) According to the SFE results, applying CNF as an asphalt binder modifier and CNT as an aggregate modifier enhanced the AFE of the aggregates and asphalt binder, showing that more energy is needed for rupture at the contact surface of the aggregates and asphalt binder in dry condition. The simultaneous application of $2.4 \% \mathrm{CNT}+2 \% \mathrm{CNF}$ had the strongest influence on the enhancement of AFE

(v) The SFE results also indicated that applying CNF increased the CFE amounts in the asphalt binder membrane

(vi) The DE results between asphalt binder and aggregates in the presence of water showed that using
$\mathrm{CNF}$ and CNT brought DE of the system toward zero, showing the less desire of the mixtures to be stripped. Mixtures modified with $2.4 \% \mathrm{CNT}+2 \%$ CNF enhanced the energy of the system, and stripping will occur later

(vii) Generally, the simultaneous utilization of CNT and CNF had the greatest influence on increasing the ITS and TSR of mixtures and the SFE of the asphalt binder-aggregate system

(viii) In future research, the composition of nanomaterials and polymer materials in modifying the properties of asphalt mixtures can be investigated. Also, the effect of metal-organic framework (MOF) materials in the modification of asphalt binder and other hydrophobic materials in the modification of aggregates can be explored

\section{Data Availability}

The data used to support the findings of this study are currently under embargo while the research findings are commercialized. Requests for data, 3 months after publication of this article, will be considered by the corresponding author.

\section{Conflicts of Interest}

The authors declare that they have no conflicts of interest reported in this paper.

\section{References}

[1] M. K. Pashaki, "Geomechanical properties of peat stabilized with cement and sand," International Journal of Advanced and Applied Sciences, vol. 4, no. 9, pp. 19-25, 2017. 
[2] M. Nikookar, M. K. Pashaki, and M. Arabani, "Engineering properties of stabilized soil of gisoom forest area using cement-sand mixture," Advances in Civil and Environmental Engineering, vol. 02, no. 3, pp. 162-171, 2013.

[3] V. Najafi Moghaddam Gilani, S. M. Hosseinian, H. Behbahani, and G. H. Hamedi, "Prediction and paretobased multi-objective optimization of moisture and fatigue damages of asphalt mixtures modified with nano hydrated lime," Construction and Building Materials, vol. 261, Article ID 120509, 2020.

[4] A. Kavussi, A. Karimi, M. Mohsen et al., "Evaluating the moisture resistance of foam warm mix asphalt using image processing method," Computational Research Progress in Applied Science \& Engineering (CRPASE), vol. 3, 2017.

[5] H. Behbahan, G. H. Hamedi, V. Najafi Moghaddam Gilani, and M. Nikookar, "Improving the moisture performance of hot mix glass asphalt by high-density polyethylene as an asphalt binder modifier," International Journal of Sustainable Building Technology and Urban Development, vol. 10, no. 4, pp. 184-193, 2019.

[6] I. Bargegol, V. N. M Gilani, R. V. Nezafat, and R. N. M Gilani, "Comparison and evaluation of fatigue behavior of asphalt concrete mixtures containing different recycled additives," Computational Research Progress in Applied Science \& Engineering (CRPASE), vol. 1, no. 1, 2015.

[7] P. G. Kumar, "Application of nano silica to improve selfhealing of bitumen mixtures," Computational Research Progress in Applied Science \& Engineering (CRPASE), vol. 6, no. $4,2020$.

[8] B. Zarei and G. A. Shafabakhsh, "Dynamic analysis of composite pavement using finite element method and prediction of fatigue life," Computational Research Progress in Applied Science \& Engineering (CRPASE), vol. 4, no. 2, 2018.

[9] Z. H. Lee, S. C. Paul, S. Y. Kong, S. Susilawati, and X. Yang, "Modification of waste aggregate PET for improving the concrete properties," Advances in Civil Engineering, vol. 2019, Article ID 6942052, 10 pages, 2019.

[10] S. M. Hosseinian, V. Najafi Moghaddam Gilani, P. Mehraban Joobani, and M. Arabani, "Investigation of moisture sensitivity and conductivity properties of inductive asphalt mixtures containing steel wool fiber," Advances in Civil Engineering, vol. 2020, Article ID 8890814, 2020.

[11] H. Taherkhani and M. Tajdini, "Comparing the effects of nano-silica and hydrated lime on the properties of asphalt concrete," Construction and Building Materials, vol. 218, pp. 308-315, 2019.

[12] N. Kamboozia, M. Ameri, and S. M. Hosseinian, "Statistical analysis and accident prediction models leading to pedestrian injuries and deaths on rural roads in Iran," International Journal of Injury Control and Safety Promotion, vol. 27, no. 4, pp. 493-509, 2020.

[13] S. M. Hosseinian and V. Najafi Moghaddam Gilani, "Analysis of Factors Affecting Urban Road Accidents in Rasht Metropolis," ENG Transactions, vol. 1, no. 1, pp. 1-4, 2020.

[14] N. Kamboozia, M. Ameri, and S. M. Hosseinian, "Statistical analysis and presentation of accident prediction model leading to injuries and deaths of pedestrians in rural roads of Gilan," Journal of Transportation Research, vol. 27, 2020.

[15] N. Kamboozia, M. Ameri, and S. M. Hosseinian, "Investigation of effective factors in the severity of rural road accidents in guilan to determine the most effective factors and provide safety solutions," Road, vol. 29, no. 106, pp. 115-128, 2021.
[16] H. Behbahani, V. Najafi Moghaddam Gilani, A. Amini, N. Kamboozia, and S. M. Hosseinian, "Fuzzy-Neural Analysis of Pedestrian Flow Crossing Urban Intersections," in Proceedings of the 18th International Conference on Traffic \& Transportation Engineering, Tehran, Iran, January 2020.

[17] H. Behbahani, V. Najafi Moghaddam Gilani, R. Salehfard, and D. Safar, "Evaluation of fatigue and rutting behaviour of hot mix asphalt containing rock wool," International Journal of Civil Engineering, vol. 18, pp. 1293-1300, 2002.

[18] V. N. M. Gilani, S. M. Hosseinian, D. Safari, and M. B. Movahhed, "Investigation of the impact of deicer materials on thermodynamic parameters and its relationship with moisture susceptibility in modified asphalt mixtures by carbon nanotube," Arabian Journal for Science and Engineering, pp. 1-14, 2020.

[19] A. Diab, Z. You, Z. Hossain, and M. Zaman, "Moisture susceptibility evaluation of nanosize hydrated lime-modified asphalt-aggregate systems based on surface free energy concept," Transportation Research Record: Journal of the Transportation Research Board, vol. 2446, no. 1, pp. 52-59, 2014.

[20] F. Moghadas Nejad, "Using hydrophobic coating on aggregate surfaces to reduce moisture damage in asphalt mixture," Journal of Materials in Civil Engineering, vol. 30, no. 10, Article ID 04018238, 2018.

[21] F. Sakanlou, H. Shirmohammadi, and G. H. Hamedi, "Investigating the effect of filler types on thermodynamic parameters and their relationship with moisture sensitivity of asphalt mixes," Materials and Structures, vol. 51, no. 2, p. 39, 2018.

[22] G. H. Hamedi, "Investigating the use of nano coating over the aggregate surface on moisture damage of asphalt mixtures," International Journal of Civil Engineering, vol. 16, no. 6, pp. 659-669, 2018.

[23] J. Ji, Y. Xu, Z. Suo et al., "Moisture susceptibility of warm mix asphalt (WMA) with an organic wax additive based on X-ray computed tomography (CT) technology," Advances in Civil Engineering, vol. 2019, Article ID 7101982, 2019.

[24] K. Mirković, N. Tošić, and G. Mladenović, "Effect of different types of fly ash on properties of asphalt mixtures," Advances in Civil Engineering, vol. 2019, Article ID 8107264, 12 pages, 2019.

[25] M. R. Kakar, O. H. Meor, M. N. Akhtar et al., "Evaluating the surface free energy and moisture sensitivity of warm mix asphalt binders using dynamic contact angle," Advances in Civil Engineering, vol. 2019, Article ID 9153603, 15 pages, 2019.

[26] H. Al-Mosawe, Z. N. M. Taki, and A. H. Abed, "Evaluating Iraqi modified asphalt concrete moisture resistance based on strength ratio and fracture energy parameters," Advances in Civil Engineering, vol. 2019, Article ID 8521682, 5 pages, 2019.

[27] A. Hefer and R. Little, "Towards quantification of adhesion and water stripping in bituminous materials using modern surface energy theory," SATC, vol. 24, 2005.

[28] F. Mansour and V. Vahid, "Effect of Liquid Nano material and hydrated lime in improving the moisture behaviour of HMA," Transportation Research Procedia, vol. 17, no. 21, pp. 34-39, 2016.

[29] H. Behbahani, G. H. Hamedi, and V. N. Moghaddam Gilani, "Effects of asphalt binder modifying with nano hydrated lime on moisture susceptibility of asphalt mixtures with thermodynamically concepts," Petroleum Science and Technology, vol. 38, no. 4, pp. 297-302, 2020. 
[30] M. Sohrabi, H. Shirmohammadi, and G. H. Hamedi, "Investigating the effect of modifying aggregate surface by micronized calcium carbonate on increasing the moisture resistance of asphalt mixtures," Periodica Polytechnica Civil Engineering, vol. 63, no. 1, pp. 63-76, 2019.

[31] M. J. Khattak, A. Khattab, and H. R. Rizvi, "Characterization of carbon nano-fiber modified hot mix asphalt mixtures," Construction and Building Materials, vol. 40, pp. 738-745, 2013.

[32] M. J. Khattak, A. Khattab, H. R. Rizvi, and P. Zhang, "The impact of carbon nano-fiber modification on asphalt binder rheology," Construction and Building Materials, vol. 30, pp. 257-264, 2012.

[33] R. K. A. Al-Rub, Nanotechnology-based System for DamageResistant Concrete Pavements, Texas Transportation Institute, San Antonio, TX, USA, 2012.

[34] M. Gong, J. Yang, H. Yao, M. Wang, X. Niu, and J. E. Haddock, "Investigating the performance, chemical, and microstructure properties of carbon nanotube-modified asphalt binder," Road Materials and Pavement Design, vol. 19, no. 7, pp. 1499-1522, 2018.

[35] S. M. Abtahi, M. Sheikhzadeh, and S. M. Hejazi, "Fiberreinforced asphalt-concrete - a review," Construction and Building Materials, vol. 24, no. 6, pp. 871-877, 2010.

[36] H. Ziari, H. Farahani, A. Goli, and S. Sadeghpour Galooyak, "The investigation of the impact of carbon nano tube on bitumen and HMA performance," Petroleum Science and Technology, vol. 32, no. 17, pp. 2102-2108, 2014.

[37] P. Park, S. El-Tawil, S.-Y. Park, and A. E. Naaman, "Cracking resistance of fiber reinforced asphalt concrete at $-20^{\circ} \mathrm{C}$," Construction and Building Materials, vol. 81, pp. 47-57, 2015.

[38] M. Saltan, S. Terzi, and S. Karahancer, "Performance analysis of nano modified bitumen and hot mix asphalt," Construction and Building Materials, vol. 173, pp. 228-237, 2018.

[39] D.-Y. Yoo, S. Kim, M.-J. Kim, D. Kim, and H.-O. Shin, "Selfhealing capability of asphalt concrete with carbon-based materials," Journal of Materials Research and Technology, vol. 8, no. 1, pp. 827-839, 2019.

[40] A. Ameli, E. Hassanzadeh Khabbaz, R. Babagoli, N. Norouzi, and K. Valipourian, "Evaluation of the effect of carbon nano tube on water damage resistance of Stone matrix asphalt mixtures containing polyphosphoric acid and styrene butadiene rubber," Construction and Building Materials, vol. 261, Article ID 119946, 2020.

[41] N. Amini and P. Hayati, "Effects of $\mathrm{CuO}$ nanoparticles as phase change material on chemical, thermal and mechanical properties of asphalt binder and mixture," Construction and Building Materials, vol. 251, Article ID 118996, 2020.

[42] M. R. Kakar, M. O. Hamzah, M. N. Akhtar, and D. Woodward, "Surface free energy and moisture susceptibility evaluation of asphalt binders modified with surfactantbased chemical additive," Journal of Cleaner Production, vol. 112, pp. 2342-2353, 2016.

[43] G. H. Hamedi, M. Asadi, F. Moghadas Nejad, and M. R. Esmaeeli, "Applying asphalt binder modifier in reducing moisture-induced damage of asphalt mixtures," European Journal of Environmental and Civil Engineering, vol. 93, pp. 1-18, 2019.

[44] ASTM International, Standard Test Method for Resistance to Plastic Flow of Bituminous Mixtures Using Marshall Apparatus (6 Inch-Diameter Specimen), ASTM International, West Conshohocken, PA, 2013.
[45] ASTM International, Standard Test Method for Penetration of Bituminous Materials, ASTM International, West Conshohocken, PA, 2013.

[46] ASTM International, Standard Test Method for Softening Point of Bitumen (Ring-and-Ball Apparatus), ASTM International, West Conshohocken, PA, 2014.

[47] M. Ameri and D. Nasr, "Properties of asphalt modified with devulcanized polyethylene terephthalate," Petroleum Science and Technology, vol. 34, no. 16, pp. 1424-1430, 2016.

[48] G. H. Hamedi, A. Sahraei, and M. R. Esmaeeli, "Investigate the effect of using polymeric anti-stripping additives on moisture damage of hot mix asphalt," European Journal of Environmental and Civil Engineering, vol. 25, pp. 1-14, 2018.

[49] V. Najafi Moghaddam Gilani, S. M. Hosseinian, and M. Nikookar, "Presentation of a new deicer with the least moisture and fatigue failures in asphalt mixtures," Arabian Journal for Science and Engineering, vol. 60, 2021.

[50] G. H. Hamedi, Z. Ranjbar Pirbasti, and N. Esmaeili, "Laboratory investigation of the effect of ABS polymer on moisture susceptibility of asphalt mixtures," Australian Journal of Civil Engineering, vol. 17, no. 2, pp. 96-109, 2019.

[51] A. G. Mahani, P. Bazoobandi, S. M. Hosseinian, and H. Ziari, "Experimental investigation and multi-objective optimization of fracture properties of asphalt mixtures containing nanocalcium carbonate," Construction and Building Materials, vol. 285, Article ID 122876, 2021.

[52] A. W. Hefer, Adhesion in Bitumen-Aggregate Systems and Quantification of the Effect of Water on the Adhesive Bond, Texas A\&M University, Texas, USA, 2005.

[53] D. N. Little and A. Bhasin, Using Surface Energy Measurements to Select Materials for Asphalt Pavement, Texas A\&M University, Texas, USA, 2006.

[54] R. J. Good and C. J. van Oss, "The modern theory of contact angles and the hydrogen bond components of surface energies," in Modern Approaches to Wettability, pp. 1-27, Springer, Berlin, Germany, 1992.

[55] G. H. Hamedi, M. R. Esmaeeli, V. Najafi Moghaddam Gilani, and S. M. Hosseinian, "The effect of aggregate-forming minerals on thermodynamic parameters using surface free energy concept and its relationship with the moisture susceptibility of asphalt mixtures," Advances in Civil Engineering, vol. 2021, Article ID 8818681, 15 pages, 2021. 